\title{
Modelling and Analysis About a Fault State of a New Cockpit Control Mechanism
}

\author{
Jingru Wang ${ }^{1, *}$, Sen Liang ${ }^{1,2}$ \\ ${ }^{1}$ Flight Control Department, AVIC XAC Commercial Aircraft CO., LTD, Xi'an City, China \\ ${ }^{2}$ Flight Control Department, First Aircraft Design Institute, Xi'an City, China \\ Email address: \\ wjr3434@163.com (Jingru Wang),wyx3434@yahoo.com (Sen Liang) \\ ${ }^{*}$ Corresponding author
}

To cite this article:

Jingru Wang, Sen Liang. Modelling and Analysis About a Fault State of a New Cockpit Control Mechanism. American Journal of Aerospace Engineering. Vol. 6, No. 1, 2019, pp. 17-23. doi: 10.11648/j.ajae.20190601.13

Received: July 17, 2019; Accepted: August 19, 2019; Published: September 4, 2019

\begin{abstract}
In the process of aircraft development, the assessment of handling quality is particularly step for verifying the cockpit control units design whether meets the design requirements or not. If the assess results are not met the design requirements, the design must to be optimized or even redesigned. At present, most of research is mainly related to the design of cockpit control units and simulating and assessment of their maneuverability based on the dynamic model in the normal mode, however, the research on handling quality of cockpit control units in the failure operating mode is seldom. Moreover, override rod linkage form as a new kind of cockpit control units brings plenty of profits such as the weight saved and maintainability improved, however, it causes the failure mode becomes diverse and complicated. Therefore it will increase the difficulty of assessing this kind of cockpit control units. The object of this paper is to do a research on working principle and physical characteristics of cockpit control units of override rod linkage form, through modeling and simulation on its normal operating mode and failure mode, and finally gives an analysis and evaluation for the column force quality of each failure mode. The simulation results reveal the column force quality of each failure mode is acceptable.
\end{abstract}

Keywords: Fly-By-Wire Civil Aircraft, Cockpit Control Units, Override Rod, Failure Mode, Flight Quality Evaluation

\section{Introduction}

The primary goal of civil aircraft design is to obtain satisfactory flight performance and excellent flight control characteristics, so the assessment for the handling performance of the aircraft is particularly important at the beginning of the design. Moreover, in the development of civil aircraft, the handling performance in the failure operating mode is also an important issue to be considered.

At present, most of research is mainly related to the design of cockpit control units $[10,13]$ and simulating and assessment of their maneuverability based on the dynamic model [7] in the normal mode, however, the research on handling quality of cockpit control units in the failure operating mode is seldom.

Comparing to the traditional design of cockpit control units, override rod linkage form adopted in the cockpit control units can solve some problems brought by the traditional cockpit control units such as complex structure, heavy weight and the disengage of the linkage between the two side control columns cannot be recovered in the air unless on the ground. It is very dangerous the aircraft with some failure flies in the air. However, the failure mode of the override rod mechanism is diverse and complicated, so the modeling of this mechanism and the evaluation of the handling qualities are relatively complicated.

In this thesis, the normal mode and failure mode model of the control cockpit units adopting the override rod are established, and the performance under various failure modes are analyzed, which provides the basis knowledge for the subsequent design of the operating mechanism.

\section{Introduction of Cockpit Control Units}

The cockpit control units can be grouped into three axis such as pith, roll and yaw. Due to the similar principle among these three axis units, this paper only describes the pitch axis 
(control column mechanism system).

\subsection{Introduction of Control Column Mechanism System}

The control column mechanism system includes a trim, an override rod and left and right control columns. The trim is to balance the force of control column. The override rod is connected to the left and right control columns. The left and right control columns control the elevator so that control the pitch movement of the aircraft [12]. Therefore, the following three types of failures exist in its operating mechanism:

1) Trim mechanism failure

2) Override rod mechanism failure

3) Left and right column control mechanism failure

\subsection{Composition of Control Column Force}

Compared with mechanically operated aircraft, the fly-by-wire aircraft makes it impossible for the pilot to directly feel the surface load of the aircraft $[3,9]$. In order to avoid the mis-manipulation of the pilot which will affect flight safety, a reasonable control force is a highly important factor for aircraft safety [1]. The force-feel system of a fly-by-wire aircraft force mainly includes a static force-feel system and a dynamic force-feel system.

The static force-feel system is related to the control displacement of the control column. It includes: breakout force, spring force and dynamic friction force [7].

Breakout force makes the control column to maintain a neutral position. It mainly comes from the static friction and pre-tightening force of the mechanical system itself. If the pilot controls the control column from stationary to moving, there will be a force which is the breakout force.

The spring force simulates the change in surface load caused by changes in the control column displacement because of manipulation of the pilot. The essence is to relay on the elastic deformation of the spring to simulate the force varying as the amount of the manipulation displacement. The longer of the manipulation displacement is, the bigger of the spring force will be.

Dynamic friction is determined by the mechanical properties of the system. It is related to the roughness and relative pressure of the contact surface. Generally, the greater the operating force is, the greater the dynamic friction will be. When the aircraft makes a large-scale action such as air collision, the dynamic friction becomes relatively large at this time.

The dynamic force system mainly refers to the damping force which is related to the control speed. The damping force will be greater as the motion speed of control column increases [2]. The force-feel envelope is shown in Figure 1.

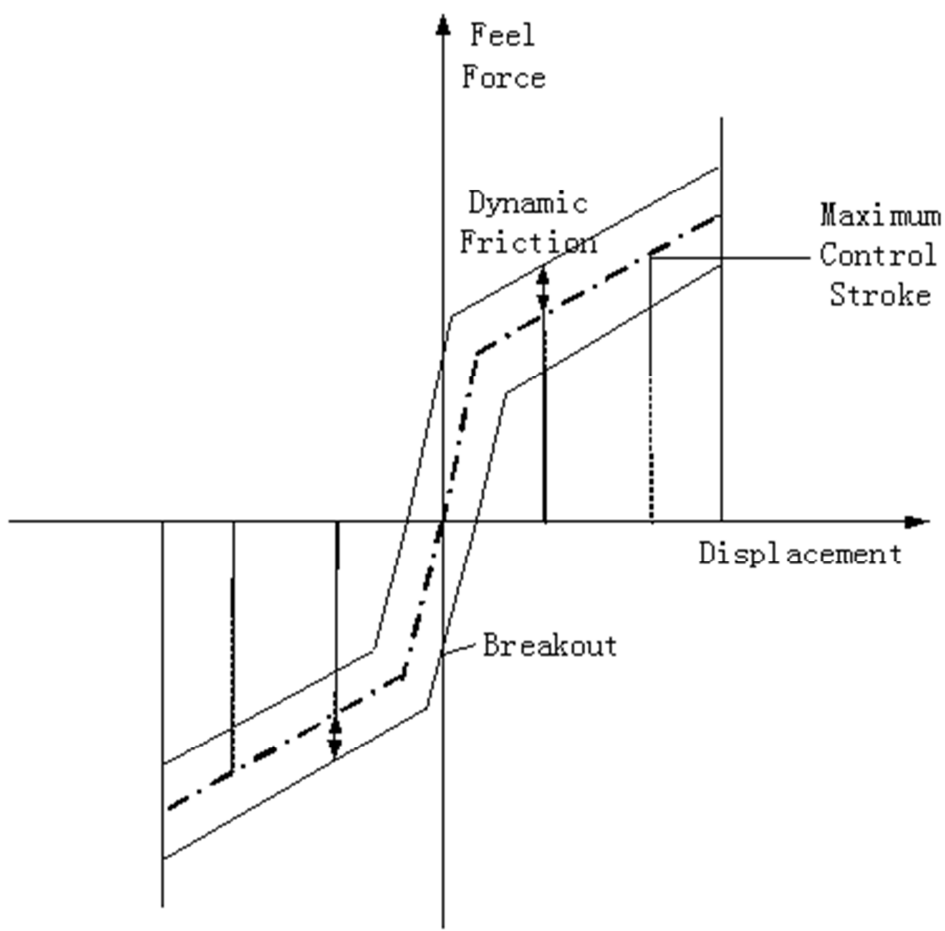

Figure 1. Feel Force Envelope.

\section{Control Column Mechanism Modeling}

\subsection{Modeling of Control Column Mechanism in Normal Operating Mode}

According to the above description, the force-feel system of the control column mechanism mainly includes a static force-feel system and a dynamic force-feel system. Only when the movement speed of the control column is not equal to 0 , the dynamic force will exist [8]. This paper only researches the condition of static balance. That is all of modelling is based on damping force is 0 . And the equivalent physical model of the control column mechanism can be obtained: two springs of control column mechanism and a spring of override rod [4], which are shown in Figure 2. 


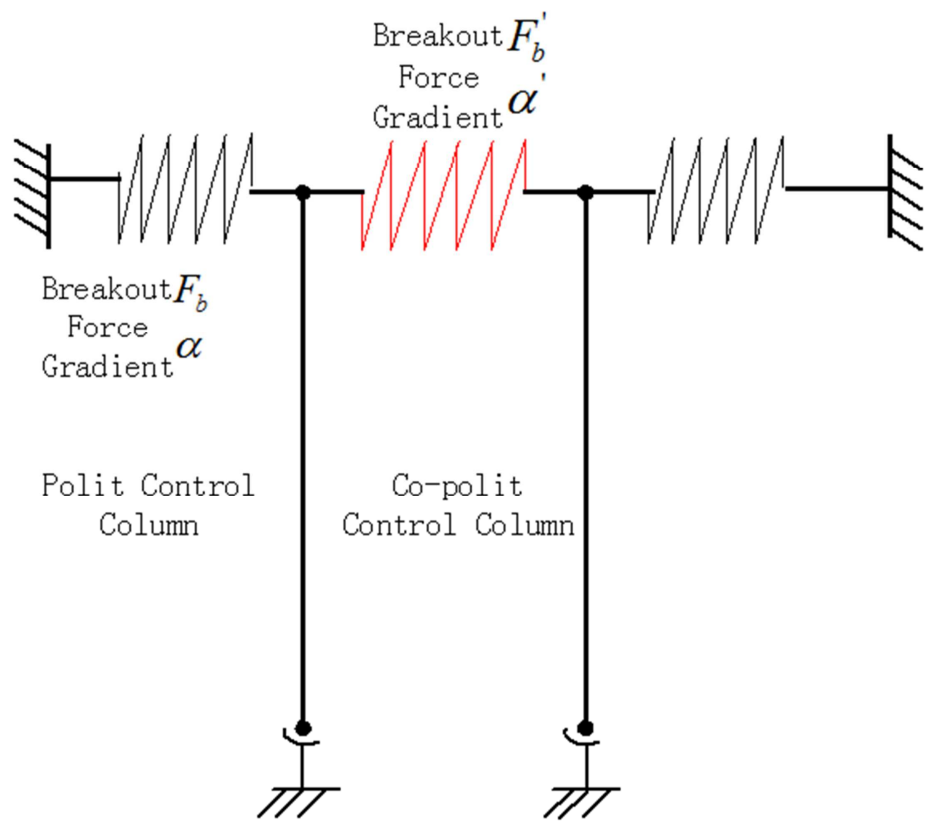

Figure 2. The Equivalent Physical Model of Column Control Mechanism of the Normal Mode.

According to the force-feel law [6], if the control column is at a certain position, the control force at the control column is twice the output spring force of the one-side control column. Therefore, the model for the force-displacement of the control column in the normal operating mode can be established, as shown in Figure 3.

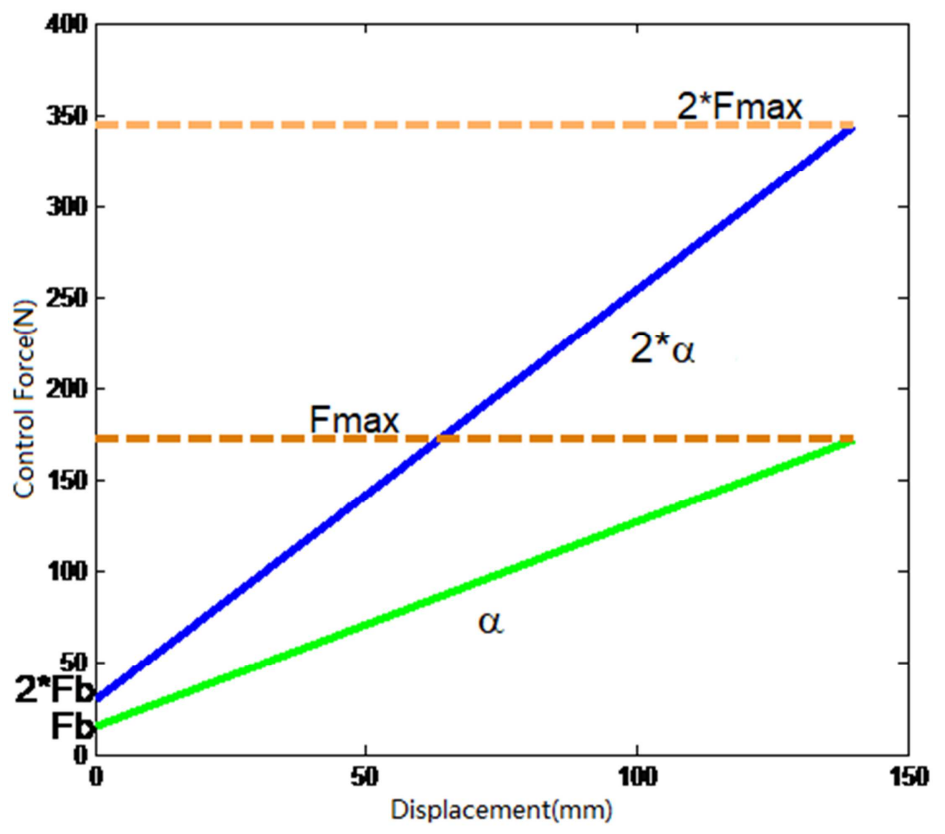

Figure 3. Column Force and Column Displacement Curve of Normal Model.

\subsection{Modeling of Control Column Mechanism in Failure Mode}

\subsubsection{The Failure Mode of Trim Mechanism}

According to Section 2, there are three types of failure in the cockpit control mechanism. For the category 1) of failure, the failure of the trim module just can't trim the control force of the control column, so that the pilot can only control the aircraft with certain amount of force all the time which increases the work burden to the pilots. The model of control column mechanism under this failure condition is equivalent to the normal operating mode, as shown in Figure $32 \alpha$ normal operating mode.

\subsubsection{The Failure Mode of Override Rod Mechanism}

For the category 2) of failure, the override rod failure can be divided into:

1) Jamming of the override rod

When the override rod is jammed, the two sides of the control column can still operate normally. When one side of 
control column fails, the override rod can no longer be disconnected. Under this failure condition, the model is equivalent to force-displacement of the control column in the normal operating mode, as described in Figure 3 of $2 \alpha$ normal operating mode. Therefore, the pilot's control force is equal to the sum of the spring force of the control column mechanisms on both sides in the normal operating mode.

2) Rupture of the override rod

When the override rod is ruptured, it is equivalent to the two sides of the control column being disconnected and operating independently. The model under this fault condition can be equivalent to the force-displacement model of the single-side control column mechanism, as shown in Figure 3 of the single-side load mechanism.

\subsubsection{The Failure Mode of Control Column Mechanism in Failure Mode}

For the category 3) of failure, when one side control column mechanism failure (jamming), the failure-side control column will be disconnected by the override rod and only the normal-side control column is operated. Due to the particularity of the override rod, this paper mainly analyzes this kind of failure.

When the one-side control column mechanism is jammed, the control column mechanism is equivalent to control column mechanism on the normal operating side plus the override rod mechanism, and the physical model can be equivalent to the following figure 4.

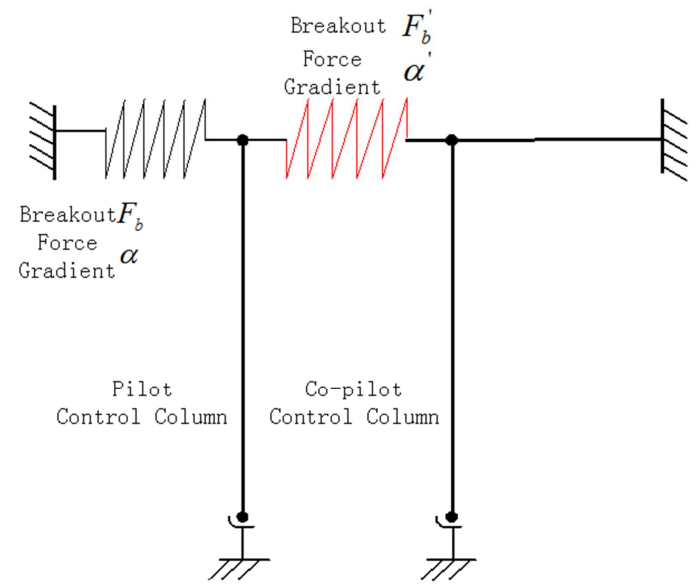

Figure 4. The Equivalent Physical Model of Control Mechanism of One-side Control Column in the Jam Mode.

According to the physical characteristics of the override rod, that is, the neutral point of its spring varies with the position of the jamming. Hence, the failure modes can be grouped into the following categories:

1) Push forward after jamming

Assuming that the force gradient of the one-side control column mechanism is $\alpha$, then according to the above analysis, the force gradient of the control column in the normal operating mode should be $2 \alpha$. When one-side control column is jammed, the current force of the control column is $F_{\alpha j a m}$. When the pilot pushes the control column, the pilot needs to overcome the override force $F_{b}^{\prime}$ of the override rod and the current jamming force of the control column. The force gradient of control column after override is the force gradient of the override rod plus the force gradient of the single side control column $\left(\alpha+\alpha^{\prime}\right)$. The model for the force-displacement of the control column is shown in Figure 5.

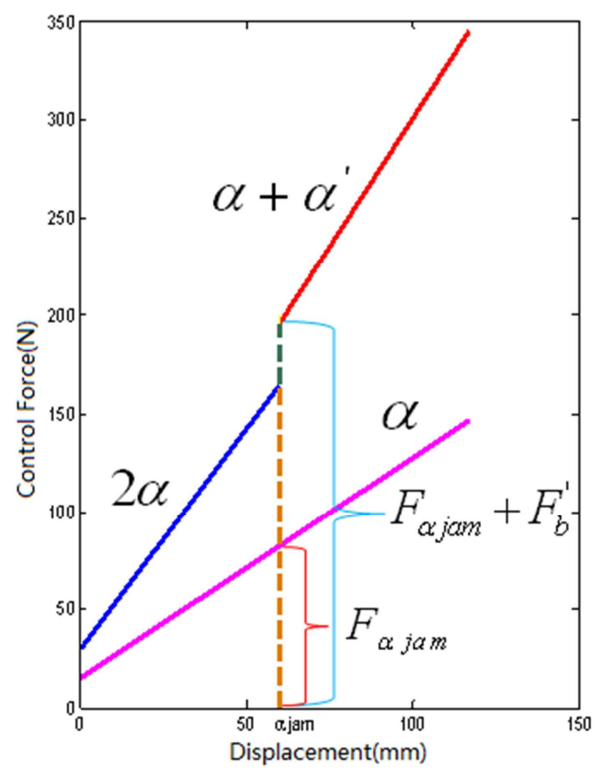

Figure 5. Control Force-Displacement Model of Push under Jam in the Middle Position.

2) Pull back after jamming

When the pilot pulls control column from the jamming position, the force of the single-side control column is to help the pilot achieve the override. Therefore, the pilot needs to overcome the override force $\left(F_{b}^{\prime}\right)$ minus the current force of control column $\left(F_{\alpha j a m}\right)$. Moreover, the force gradient after the override is force gradient of override rod minus the force gradient of the one-side control column $\left(\alpha^{\prime}-\alpha\right)$. The displacement model of the rod is shown in Figure 6.

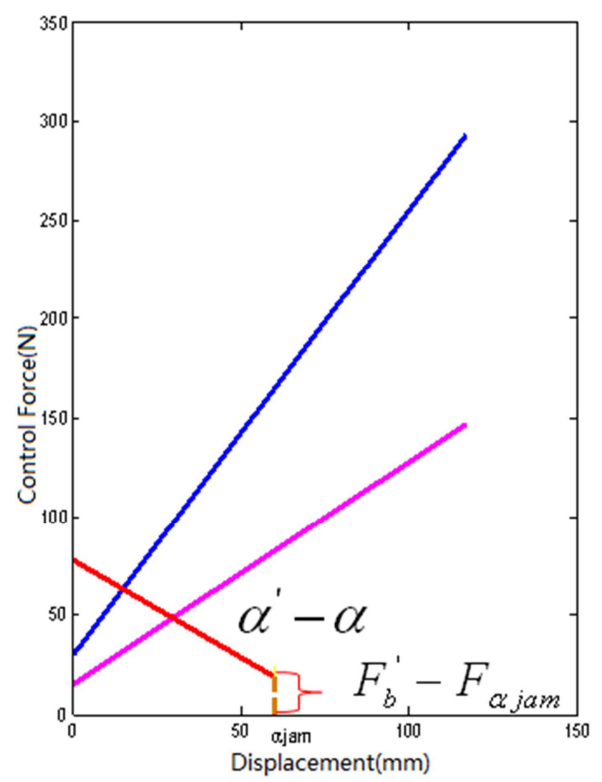

Figure 6. Control Force-Displacement Model of Pull under Jam in the Middle Position. 
3) Jam at the front limited position

This belongs to category 2), which is the limited situation that the pilot pulls-back when the one-side control column is jammed at the maximum forward position.

4) Jam at the back limited position

This belongs to category 1), which is the limited situation that the pilot pushes-forward when the one-side control column is jammed at the maximum backward position.

5) Jam at the trim position

This case is a situation that one-side control column is jammed after trim. It can be considered the translation of the trimming position in cases 1) and 2). The force- displacement model in this case is shown in Figures 7 and 8.

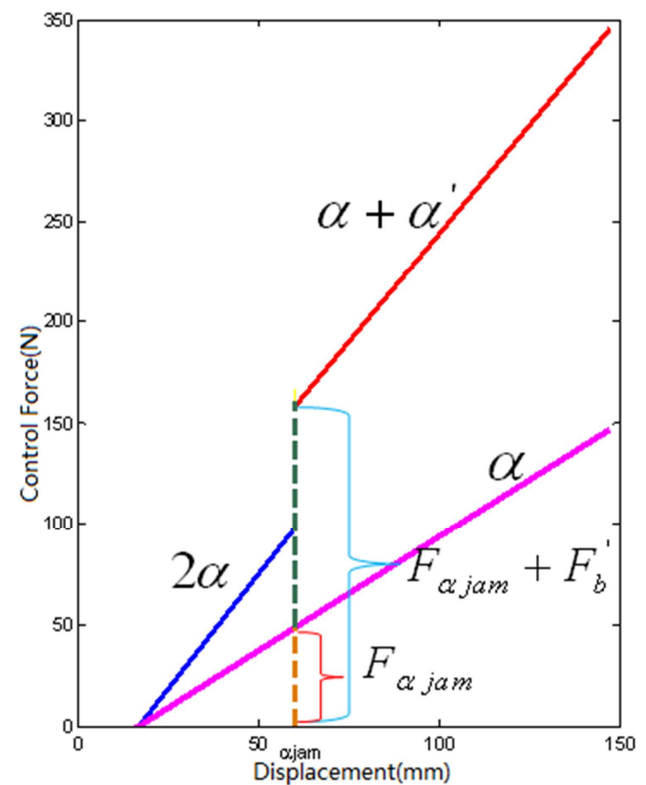

Figure 7. Control Force - Displacement Model of Push under Jam in the Middle Trim Position.

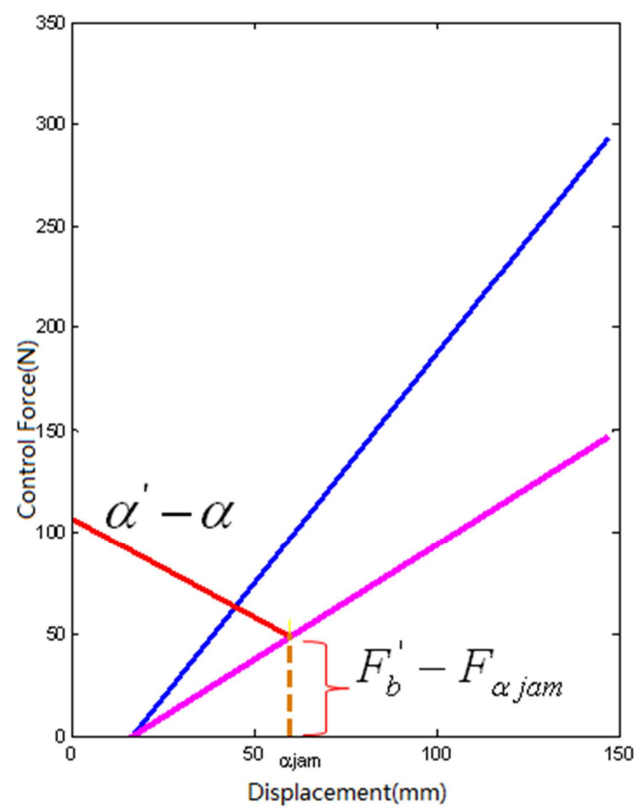

Figure 8. Control Force and Displacement Model of Pull under Jam in the Middle Trim Position.

\section{Flight Quality Assessment of Control Column Mechanism}

The force-displacement characteristics of the control column directly affect the aircraft's flight quality in the pitch axis. Compare to the normal operating mode, the force-displacement characteristics will change greatly under the failure mode.

\subsection{Requirement of Flight Quality}

The gradient of control force and normal load is a key point to measure the force-displacement maneuvering performance. The requirements [15] is described in Table 1.

Table 1. Flight qualities requirement of gradient of control force and normal load.

\begin{tabular}{|c|c|c|}
\hline Level & Maximum gradient & $\begin{array}{l}\text { Minimum } \\
\text { gradient }\end{array}$ \\
\hline Level 1 & $\frac{2270}{n / \alpha}$ but no more than 540 and no less than 360 & 107 \\
\hline Level 2 & $\frac{3500}{n / \alpha}$ but no more than 825 and no less than 550 & 91 \\
\hline Level 3 & 1090 & 23 \\
\hline
\end{tabular}

\subsection{Assessment Results of Control Column Mechanism in} Failure Mode

This paper selects the different operating points based on various airspeeds and altitudes in cruise phase and evaluates the flight quality of control force and normal load under the following failure conditions.

1) One-side control column is jammed at the neutral position

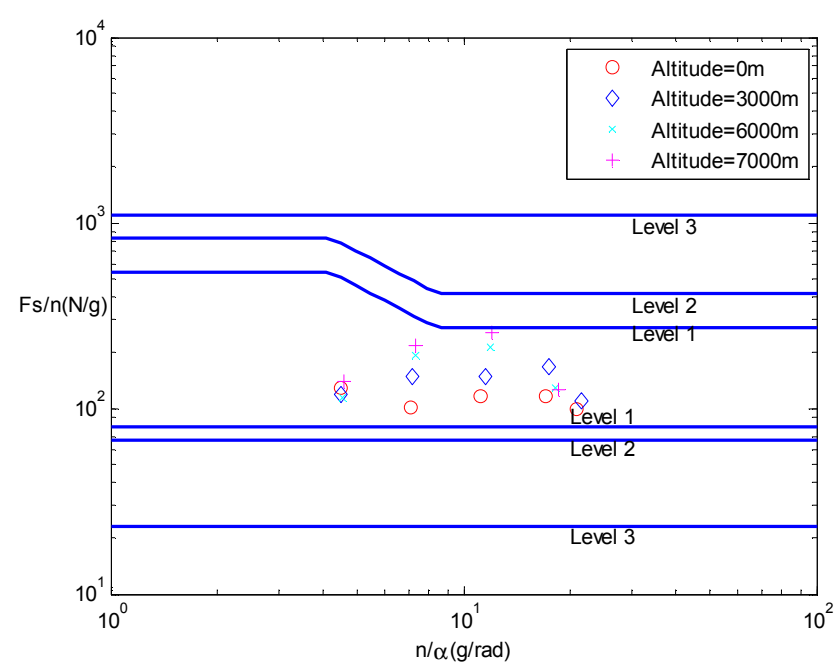

Figure 9. The evaluated result of the flight quality of control force VS. normal load.

2) One-side control column is jammed at the back limited position 


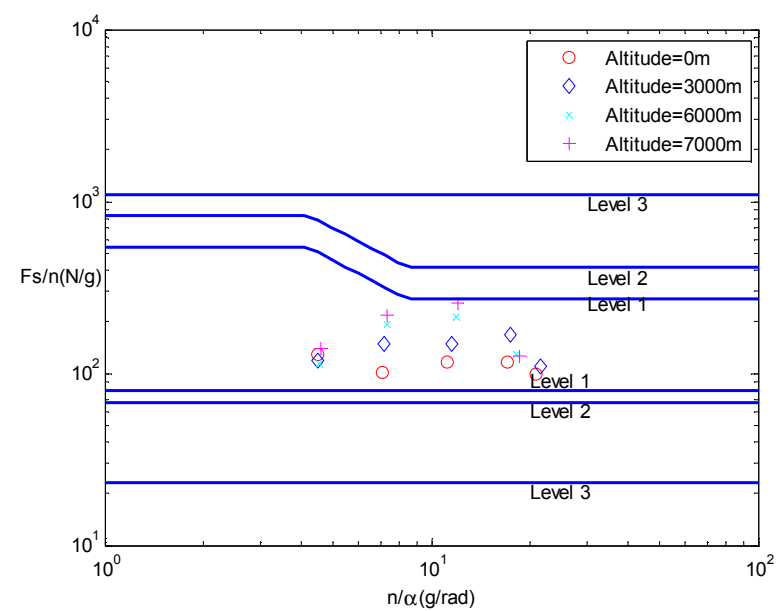

Figure 10. The evaluated result of the flight quality of control force VS. normal load.

3) One-side control column is jammed at the front limited position

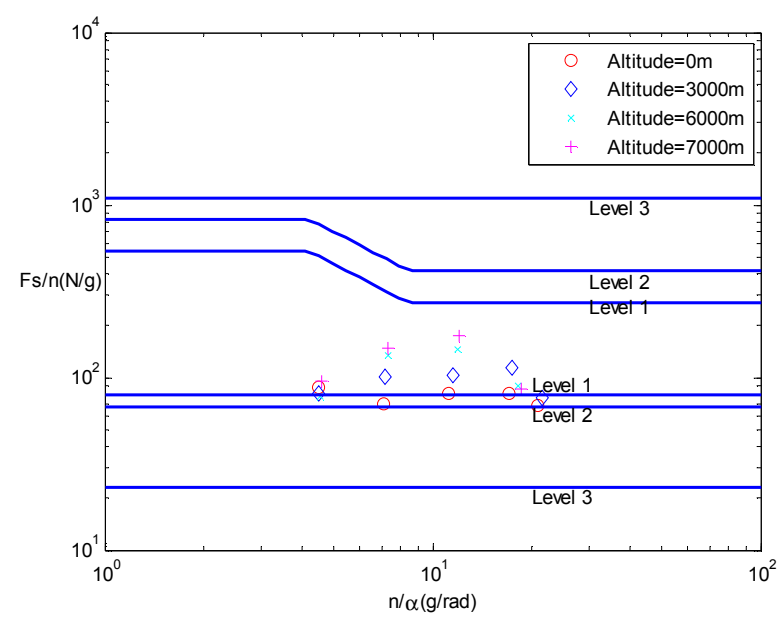

Figure 11. The evaluated result of the flight quality of control force VS. normal load.

4) One-side control column is jammed at $30 \mathrm{~mm}$ trimming and back limited jamming position

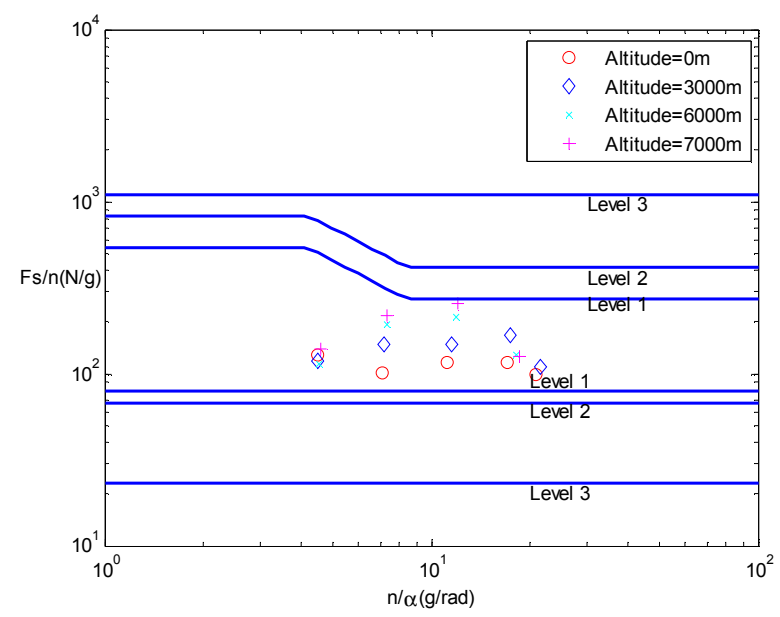

Figure 12. The evaluated result of the flight quality of control force VS. normal load.
5) One-side control column is jammed at $-40 \mathrm{~mm}$ trim and front limited jamming position

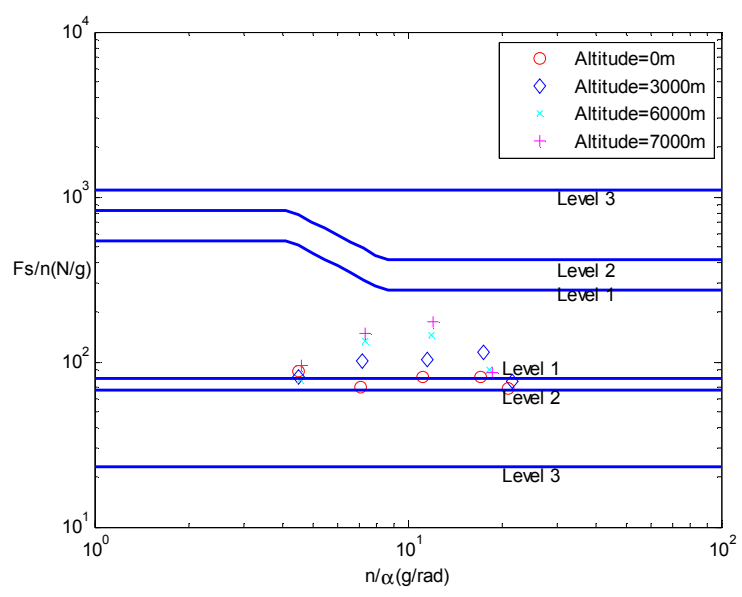

Figure 13. The evaluated result of the flight quality of control force VS. normal load.

From the above evaluation results of various failure conditions, it can be seen that most of operating points of the flight quality of control force and normal load fall to the first-level quality area, and a few fall to the second-level quality area. This problem can be solved by compensating the control force to improve the flight quality. Moreover, the evaluation results of the failure modes such as1),2) and 4) are almost same, and the results of 3) and 5) are same, because the flight quality of control force VS. normal load only depends on relationship between the control force gradient and the normal load.

\section{Conclusion}

In this paper, a new type of override rod cockpit control mechanism is analyzed and the mathematical model of the control force-displacement under different working conditions is established according to its working principle. Moreover, the control force and normal load characteristic is simulated and evaluated by the established mathematical model. The results show that the flight quality of control force and normal load of the control column mechanism in failure mode can reach the first-level quality under most working conditions. For those in secondary-level, its flight quality can be improved by increasing the force gradient of the control column mechanism and the override rod.

\section{Acknowledgements}

Due to limitation of my work area, I am not familiar with some principle in mechanical area. Thanks to my husband Sen Liang who gave me plenty of technical suggestions.

\section{References}

[1] Song Xianggui, Zhang Guoxin. Fly-by-Wire Flight Control System [M]. Beijing, National Defence Industrial Press, 2003: 7-9. 
[2] Shen Yongkui, Wu Mei, Chen Lan, An Jinwen. Modeling and Simulation of Vehicle Control System [J]. Fire Control and Command Control, 2005, 30 (3): 98-104.

[3] Li Hao, Wang Haiyan. The New Development of Fly-by-Wire Control System in Civil aircraft [J]. Journal of Civil Aviation University of China, 2000 (6): 8-11.

[4] Zheng Shutao, Liao Feng, Wang Liwen. Experimental Study of Control Loading System of the Flight Simulator [J]. Journal of System Simulation, 2008, 20 (4): 965-969.

[5] Zhang Chong, Xue Ying, Guo Jianwei. Simulation Research on Disengagement Force of Column Mechanism of Civil aircraft [J]. Science and Technology Innovation Herald, 2013, 26 (3): 23-24.

[6] Yu Liming, Wang Zhanlin, Qiu Lihua. Simulation Research on Flight Control System Modeling and Order Reduction [J]. Computer Simulation, 2000, 17 (3): 15-18.

[7] Tian Jinqiang, Xue Ying, Guo Jianwei. The Kinetics Simulation of Fly-by-Wire Aircraft Control Column System [J] Civil Aircraft Design and Research Institute, 2012, 25 (3): 53-56.

[8] Zhang Yusong. Study on Control Loading System in Flight Simulator Base on the Electro-Motive [D]. Tianjin: Civil Aviation University of China, 2009.

[9] Sun Guoqing, Lv Ming. Analysis of Fly-by-Wire Control System [J]. Mechanical and Electronic, 2008, (18): 444.

[10] Wang Junlong. Research on Mechanism Structure and Control Scheme of Active Side-stick in Aeroplane [D]. Nanjing: Nanjing University of Aeronautics and Astronautics, 2008
[11] Wang Ting, Zou Quan Liu Yan. Flight Test Method Study on Civil Aircraft Primary Flight Control Surfaces Jamming [J]. Xi'an: Advances in Aeronautical Science and Engineering, 2014.

[12] Zhang Fang, The Operating Components in Cockpit of Fly-by-Wire Flight Control System Research [J]. Beijing: China Aeronautical academy, 2014.

[13] Lin Fengjun. Design and analysis of CRJ200 aircraft flight control system [J]. Shanghai: Design and research of civil aircraft, 2001, 4, 32-39.

[14] Ding Zuoquan. Active Side-stick Control System for Aeroplane [D]. Nanjing: Nanjing University of Aeronautics and Astronautics, 2011.

[15] Gao Jinyuan, Li Luyu, Feng Yachang. Aircraft Handing Qualities [M]. Beijing: National Defence Industry Press, 2003: 31-47.

[16] Tom Berger and Mark B. Handling Qualities Flight Test Assessment of a Business Jet NzU P- $\beta$ Fly-By-Wire Control System [J]. American Institute of Aeronautics and Astronautics, 2017.

[17] Berger, T., Tischler, M. B., Hagerott, S. G., Cotting, M. C., Gresham, J. L., George, J. E., Krogh, K. J., D'Argenio, A., and Howland, J. D., "Development and Validation of a Flight Identified Business Jet Simulation Model Using a Stitching Architecture," AIAA Modeling and Simulation Technologies Conference, Grapevine, TX, January 2017. 